\title{
The AMS Review
}

\author{
Victoria Crittenden • Robert A. Peterson
}

Revised: 1 January 2011 /Accepted: 1 January 2011 /Published online: 19 May 2011

(C) Academy of Marketing Science 2011

Welcome to the inaugural issue of the AMS Review! As set forth by the Academy of Marketing Science and noted on the journal's website (http://amsr.edmgr.com), the aim and scope of the Review is to:

...publish thoughtful contributions that offer insights and perspectives extending knowledge and understanding of marketing-related phenomena. The Review is receptive to different philosophical perspectives and levels of analysis that range from micro to macro. Especially welcome are manuscripts that integrate research and theory from non-marketing disciplines such as management, sociology, economics, psychology, geography, anthropology, or other behavioral sciences. Examples of suitable manuscripts include those incorporating conceptual and organizing frameworks or models; those extending, comparing, or critically evaluating existing theories or models; and those suggesting new or innovative theories or models. Comprehensive and integrative quantitative syntheses of research literatures (i.e., meta-analyses) are appropriate.

As such, the AMS Review possesses goals similar to The Academy of Management Review and Psychological Review and, like these scholarly publications, does not publish empirically based research.

The genesis of the Review was the recognition by the Academy of Marketing Science leadership several years

\section{Crittenden $(\bowtie)$}

Carroll School of Management, Boston College,

Fulton Hall 450B, 140 Commonwealth Ave.,

Chestnut Hill, MA 02467, USA

e-mail: victoria.crittenden@bc.edu

\section{R. A. Peterson}

Office of the Vice President for Research,

The University of Texas at Austin,

Austin, TX 78713, USA

e-mail: rap@mail.utexas.edu ago that the marketing discipline was being underserved by existing journals when it came to contributions that focused on comprehensive and evaluative literature reviews, conceptual models, and theory creation and development. Consequently, the Academy created the AMS Review to proactively address this lacuna.

The concern over the lack of conceptual and theoretical advancements has been corroborated by a recent Journal of Marketing article by Yadav (2010). In the article, Yadav provided a detailed examination of publishing trends in marketing's major journals. Based on his analysis, there were only 818 "conceptual" articles - articles not reporting empirical research-out of a total of 5,520 articles published in Journal of Marketing, Journal of Marketing Research, Journal of Consumer Research, Marketing Science, and Journal of the Academy of Marketing Science over a 30 year period from 1978 to 2007. Unfortunately, even with this low ratio of conceptual to empirical articles, the data revealed a declining trend in the publication of conceptual articles beginning in 1993.

Interestingly, the lack of conceptual and theoretical advancements might lie in part with the training of doctoral students in marketing. Yadav offered informal, anecdotal evidence to suggest that doctoral training in marketing increasingly emphasizes statistical techniques and empirical research to the detriment of conceptual and theoretical research. This evidence led to a review of doctoral program course offerings by the co-editors.

\section{Doctoral training}

The American Marketing Association hosts a website listing doctoral programs that allow students to specialize in marketing. As of the fall of 2010 , there were 184 such doctoral programs on the list categorized by geographic location: 
- $\quad$ Asia $=7$ programs

- $\quad$ Australia/New Zealand $=18$ programs

- Canada $=11$ programs

- $\quad$ Europe $=41$ programs

- $\quad$ United States $=107$ programs

For each of the doctoral programs listed on the AMA website, a detailed review of the program's website was undertaken to determine if the marketing program offers a "theory course" (as a "proxy" for a course that might relate to the content and mission of the Review) and, then, if that "theory course" is required for marketing doctoral students or is an elective course. In instances in which program detail was insufficient on the website, a faculty member in the program was contacted for clarification. Of the 184 programs examined, 49 require a "theory course" and 19 offer an elective "theory course." The "theory courses" are most often referred to as "Marketing Theory," although other representative course titles include "Philosophy of Science," "Organizational Theory," "Management Theory," and "Business Inquiry."

If the programs on the AMA website are representative of marketing doctoral programs worldwide, only slightly more than $26 \%$ of marketing scholars-to-be has taken a required marketing theory course. That percentage increases to about $37 \%$ if an elective marketing theory course is considered. Thus anywhere from $63 \%$ to $74 \%$ of marketing doctoral students has never taken a doctoral-level marketing theory course.

Yadav (2010), and earlier Gummesson (2001), attributed the lack of conceptual knowledge in marketing to the content and structure of doctoral program curricula, and the present analysis of marketing doctoral programs provides support for just such a demise in conceptual knowledge development. To quote Gummesson (2001), p. 42, "The majority of business schools in the world teach and do research as if statistical techniques and deductive research were the only genuine science." Thus, although multiple methodology courses are both required and plentiful, conceptually focused courses are not the norm in marketing doctoral programs. While marketing doctoral students are taught how to test a theory or hypotheses or parameterize a model, they are not taught how to properly create or develop a theory or conceptual model.

Whereas the demise of theory creation and development is epitomized by marketing doctoral programs, the marketing professoriate has to take responsibility for the conceptual and theoretical lacuna that now exists. It has been almost five decades since Taylor (1965) described three areas in which marketers could accrue great benefits: (1) the development of conceptual schemes that open new frontiers in marketing knowledge, (2) the development of conceptual schemes that extend beyond knowledge for knowledge's sake and actually improve marketing practice, and (3) the continual refinement of concepts to keep pace with changing patterns and practices in the marketplace. Many such benefits are operationalized through marketing theories that help scholars structure their thoughts related to generalizing, explaining, synthesizing, and idealizing a broad range of phenomena (Price 2010; Hambrick 2007).

Hopefully the overall aims and scope of the AMS Review will encourage marketing scholars to address the conceptual and theoretical lacuna that currently exists. This first issue of the AMS Review contains four thoughtful contributions to marketing knowledge and illustrates the types of articles than can be expected in the journal.

\section{Multiple approaches to crafting marketing theory}

In "Entrepreneurship in Global Innovation Ecosystems," Zahra and Nambisan (2011) explore the role of innovation ecosystems in birthing and supporting new ventures and inducing heterogeneity among them. Within this context, the authors describe how entrepreneurial activities in these innovation ecosystems are likely to vary from those in other contexts. The implications of such ecosystems for the strategic shifts that new ventures might experience in the course of their evolution are considered, with special attention paid to the managerial challenges that new ventures may encounter in developing, leveraging, and balancing their technological and marketing capabilities.

Gundlach et al. (2011) synthesize findings from extant multi-channel research so as to better understand the primary pro-competitive justification for resale price maintenance in "Resale Price Maintenance and Free Riding: Insights from Multi-Channel Research.” Although the legal standards applicable to resale price maintenance (RPM) have resulted in an increase in its use by marketers, there continues to be a lack of contemporary research on the effects of RPM on competition. The discussion by these authors augments antitrust understanding of RPM in important and novel ways.

The literature focusing on the marketing strategy implications of product characteristics and customer characteristics is vast and extensive. Even so, Varadarajan (2011) proffers that unlike the marketing strategy implications of product characteristics that generalize to all competitors of a specific product offering, the marketing strategy implications of firm characteristics are idiosyncratic to individual competitors. A likely consequence of the heterogeneity in organizational capabilities is differences among competitors in their quality of understanding the marketing strategy implications of product characteristics. 
In turn, their marketing strategies are informed by the distinctive characteristics of the product offering. Against this backdrop, "Marketing Strategy: Perspectives on the Relative Influence of Product and Firm Characteristics" explores the relative influence of product characteristics and firm characteristics on marketing strategy.

In the final article in this inaugural issue of the $A M S$ Review, Hult et al. (2011) review the concept of stakeholder marketing. Relying on established marketing theory, in conjunction with an extensive review of the marketing literature, the authors offer a conceptual framework for understanding the pivotal role of stakeholder marketing for the future of marketing thought. To facilitate research inquiry in the area, research questions for examining the linkages among stakeholder exchanges, value creation, and marketing outcomes are suggested.

Each of the articles in this first issue of the Review makes a significant contribution to theory development in marketing, even though each follows a different framework and format when developing its theoretical contribution. Collectively the articles in this issue illustrate that there is no one best way of crafting marketing theory, which makes creating and developing theory difficult to teach and learn. The next issue of the Review will provide an overview of frameworks and schemas used when creating and develop- ing theory as well as expanding and presenting theoretical domains in the context of marketing.

\section{References}

Gummesson, E. (2001). Are current research approaches in marketing leading us astray? Marketing Theory, 1(1), 27-48.

Gundlach, G. T., Manning, K. C., \& Cannon, J. P. (2011). Resale price maintenance and free riding: insights from multi-channel research. AMS Review, 1(1). doi:10.1007/s13162-011-0005-2

Hambrick, D. C. (2007). The field of management's devotion to theory: too much of a good thing? Academy of Management Journal, 59(6), 1346-1352.

Hult, G.T.M., Mena, J.A. Ferrell, O.C., \& Ferrell, L.K. (2011). Stakeholder marketing: a definition and conceptual framework. AMS Review, 1(1). doi:10.1007/s13162-011-0002-5

Price, L. (2010). Thinking theoretically. Presentation, Academy of Marketing Science Annual Conference, Portland, Oregon, May 26-29.

Taylor, W. J. (1965). Is marketing a science? revisited. Journal of Marketing, 29, 49-53.

Varadarajan, R. (2011). Marketing strategy: perspectives on the relative influence of product and firm characteristics. $A M S$ Review, 1(1). doi:10.1007/s13162-011-0003-4

Yadav, M. S. (2010). The decline of conceptual articles and implications for knowledge development. Journal of Marketing, 74, 1-19.

Zahra, S.A, \& Nambisan, S. (2011). Entrepreneurship in global innovation ecosystems. AMS Review, 1(1). doi:10.1007/s13162011-0004-3 